\title{
Parametric Analysis on Delamination in Drilling of Wood Composite Panels
}

\author{
T. N. Valarmathi ${ }^{1 *}$, K. Palanikumar ${ }^{2}$ and S. Sekar ${ }^{3}$ \\ 1 Department of Mechanical \& Production Engineering,Sathyabama University, \\ Chennai-600 119, India; valarmathi.tn@gmail.com \\ 2 Department of Mechanical Engineering, Sri Sai Ram Institute of Technology, \\ Chennai-600 044, India; palanikumar_k@yahoo.com \\ ${ }^{3}$ Department of Mechanical Engineering, R.M.K.Engineering College, \\ Chennai-601 206, India; sekarsarav@gmail.com
}

\begin{abstract}
Composites are widely used in all the fields because of its favorable properties over conventional materials. Medium Density Fiberboard (MDF) is an extensively used wood composite in furniture industries. Drilling is the most commonly used machining process in the assembly. The surface quality of the hole depends upon the cutting conditions. The drilling damages like delamination reduces the structural reliability of the laminates and also affects the assembly of parts, appearance and the performance of the final product. The objective of this study is to analyze the influence of cutting parameters in a systematic approach on delamination in drilling of prelaminated MDF wood panels with High Speed Steel (HSS) twist drills of different diameters. The drilling experiments were planned and performed using Taguchi design. Response Surface Methodology (RSM) based mathematical model is developed to predict the influence of process parameters. The adequacy of the model is checked using Analysis of Variance (ANOVA). The results showed that the most dominant factor which influences the delamination is feed rate followed by the drill diameter.
\end{abstract}

Keywords: Wood Composite Panels, Drilling, Delamination, Taguchi Design, Response Surface Methodology (RSM).

\section{Introduction}

Wood based composites are manufactured from waste wood particles such as saw dust, mill shavings, wood chip and smaller diameter trees. Nowadays wood based composite are replacing the solid wood because, they are cheaper, denser, uniform, defect free and flexible to make products of different shapes. Medium Density Fiberboard (MDF) is a homogeneous material made from wood fibers of softwood mixed with resin and pressed to sheet form. As MDF has high strength, dimensional stability and good machinability, it finds many applications in construction and furniture works. Generally the MDF panels are coated with veneer and other plastic laminates. Drilling is the commonly used machining process in furniture assembly. The quality of drilled surface and damages are associated with machining conditions, cutting parameters, tool geometry, tool and work material, etc $[1,4,5]$. Normally drilling damages like delamination and edge chipping occur in drilling. As these damages reduce the functional performance of the product and appearance, many research works were carried out to study the influence of cutting parameters (such as cutting speed, feed rate), tool geometry and tool material, etc., in drilling of MDF panels. Aguilera et al. [1] found that high density and low chip thickness produce optimal levels of surface

* Corresponding author:

T. N. Valarmathi (valarmathi.tn@gmail.com) 
roughness in machining of MDF. Davim et al. [2, 3, 4] performed drilling tests to evaluate the delamination on two kinds of MDF panels and observed that spindle speed and feed rate were the dominant factors. They concluded that higher cutting spindle speed reduces the delamination tendency. Gaitonde et al. [5, 6] studied the influence of machining conditions on $\mathrm{F}_{\mathrm{d}}$ and concluded that feed rate followed by spindle speed were the most significant factors in minimizing the $\mathrm{F}_{\mathrm{d}}$ both at entry and exit of the holes in drilling of MDF panels. Tsao [7] optimized the drilling parameters using Taguchi method. Drilling experiments were conducted on CFRP laminates with the core - saw drill and they observed that the feed rate and spindle speed were the dominant parameters which affect the thrust force and delamination. They concluded that low feed and high spindle speed produces less thrust force and delamination. Singh et al. [8] investigated the drilling process parameters by developing a fuzzy rule based model for predicting thrust force and torque on GFRP composites with 8-facet carbide drill of three different diameters as per Taguchi's $\mathrm{L}_{27}$ orthogonal array and found that the delamination tendency can be reduced by increasing the spindle speed and keeping the feed rate and drill diameter as low. Palanikumar et al. [9] investigated the delamination in drilling of MDF and observed that the delamination can be reduced at low feed rates. Prakash and Palanikumar [10] studied the effect of drilling parameters and observed that the increase in drill diameter increases the delamination.Valarmathi and Palanikumar [11] performed drilling experiments on laminated MDF panels to minimize the delamination and found that thrust force developed in drilling can be reduced with high spindle speed and low feed rate. Valarmathi et al. $[12,13]$ conducted drilling experiments on plain and laminated MDF panels using high speed steel and carbide drills of $10 \mathrm{~mm}$ diameter with three different point angles and developed a mathematical model to evaluate the effect of drilling parameters on thrust force. They found that low feed rate and high spindle speed are the preferable cutting conditions to reduce the thrust force in drilling of MDF panels. The present investigation deals with the measurement and analysis of delamination in drilling wood composite panels.

\section{Experiment and Measurement}

\subsection{Plan of Experiments}

The experiments are performed on pre-laminated MDF of $12 \mathrm{~mm}$ thickness conforming to ISI 14587/1998 with HSS drills of diameters 6,8 and $10 \mathrm{~mm}$ on MCV-720 $\mathrm{CNC}$ vertical machining center with a maximum spindle speed of $8,000 \mathrm{rpm}$ and a maximum feed rate of 10,000 $\mathrm{mm} / \mathrm{min}$ at dry condition. Experimental set up and drills used for the experiments are shown in Figure 1. Table 1 depicts the properties of MDF composites tested. The
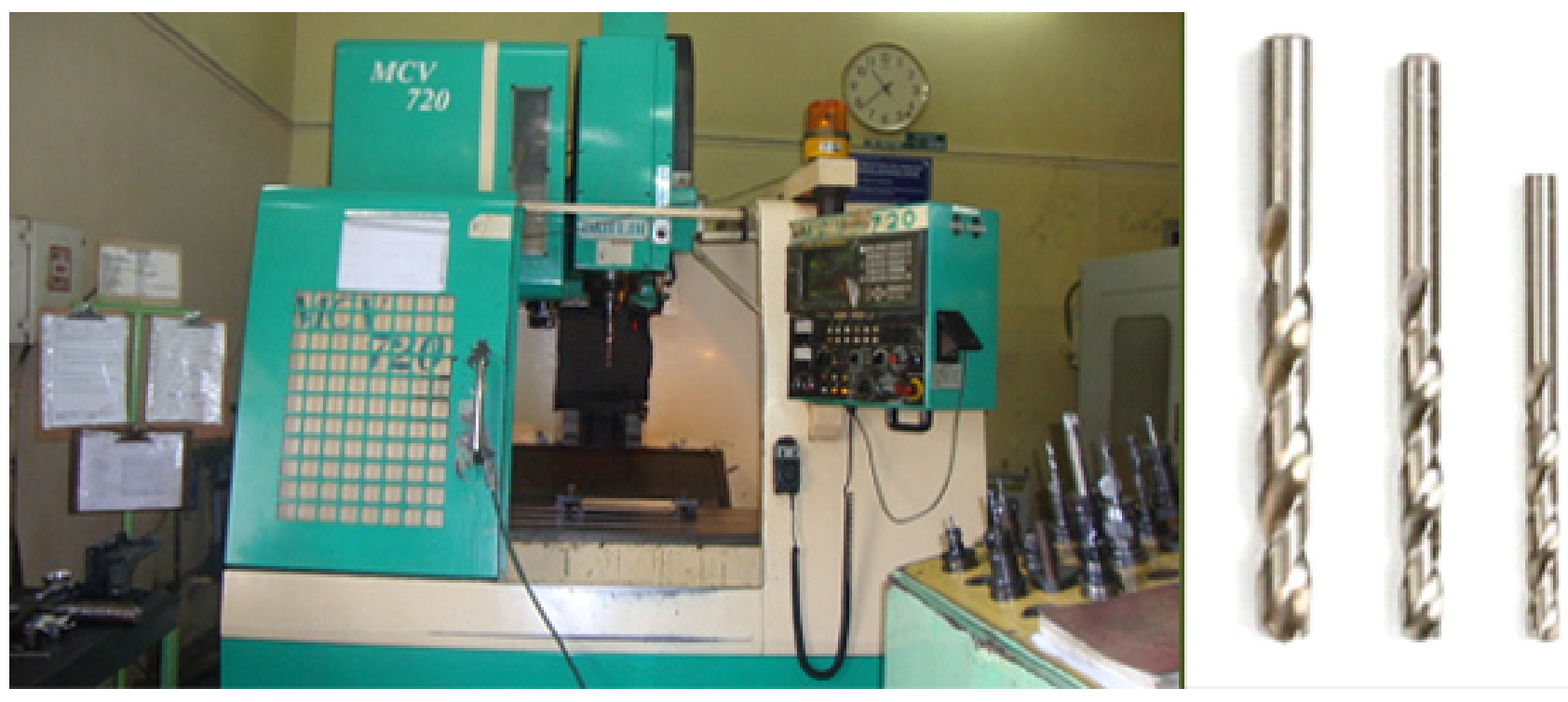

Figure 1. Experimental setup and drill bits used for the experiments. 
Table 1. Properties of MDF wood composites tested

\begin{tabular}{lccc}
$\begin{array}{l}\text { Tensile strength } \\
\left(\mathrm{N} / \mathrm{mm}^{2}\right)\end{array}$ & $\begin{array}{c}\text { Modulus of } \\
\text { Rupture }\left(\mathrm{N} / \mathrm{mm}^{2}\right)\end{array}$ & $\begin{array}{c}\text { Moisture } \\
\text { Content }(\%)\end{array}$ & $\begin{array}{c}\text { Density } \\
\left(\mathrm{Kg} / \mathrm{mm}^{3}\right)\end{array}$ \\
\hline 0.8 & 28 & $5-15$ & $730-760$ \\
\hline
\end{tabular}

Table 2. Machining parameters used and their levels

\begin{tabular}{lrrr}
\hline Parameters & \multicolumn{3}{c}{ Levels } \\
\cline { 2 - 4 } & \multicolumn{1}{c}{$\mathbf{1}$} & \multicolumn{1}{c}{$\mathbf{2}$} & \multicolumn{1}{c}{3} \\
\hline Spindle speed $(\mathrm{N} \mathrm{rpm})$ & 1500 & 3000 & 4500 \\
Feed rate $(\mathrm{f} \mathrm{mm} / \mathrm{min})$ & 100 & 200 & 300 \\
Drill diameter $(\mathrm{d} \mathrm{mm})$ & 6 & 8 & 10 \\
\hline
\end{tabular}

drilling experiments are planned and performed using Taguchi design of experiments. The cutting parameters selected for the present investigation are spindle speed (N) $\mathrm{rpm}$, feed rate (f) $\mathrm{mm} / \mathrm{min}$ and drill diameter (d) $\mathrm{mm}$. The cutting parameters and their levels are presented in Table 2.

\subsection{Measurement of Delamination}

The experiments are performed using vertical machining center. The cutting forces like thrust force, torque, etc., developed during drilling of wood composite panels try to peel-up the laminates at the entrance and push-out the laminates at the exit cause delamination damage at the entrance and exit of the drilled holes. The experiments are repeated for 3 times. The images of all the drilled holes are captured and carefully measured using CorelDRAW X5 vector graphics editor with the 'CROP' option to find out the maximum diameter of delamination at the exit as shown in Figure 2(a). The drilled holes and the scheme for delamination are presented in Figure 2(b). The average value of delamination is used to determine the $\mathrm{F}_{\mathrm{d}}$. The $\mathrm{F}_{\mathrm{d}}$ can be determined using the relation given in Equation (1) as:

$$
F_{d}=\frac{D_{\max }}{D}
$$

where $\mathrm{D}$ max $=$ maximum diameter of the damage zone and $\mathrm{D}=$ hole diameter.

\section{Results and Discussion}

Nowadays the use of wood composites like MDF, Particleboard (PB), etc. is widely increased in interior and exterior construction and furniture industries because of their favorable properties and aesthetic appearance over solid wood. Drilling is one of the main machining processes used in the fabrication process. Delamination in drilling is the major concern which affects the quality of the final product and hence it is necessary to pay much attention in reducing the tendency of delamination. In this study the influence of control parameters on delamination is determined using a mathematical model developed based on RSM and the optimal cutting conditions is obtained using Taguchi method.

\subsection{Taguchi Technique}

Taguchi method combines the engineering and statistical methods to attain rapid improvements in quality and cost by optimizing product design and manufacturing processes. Taguchi method can be effectively used to determine the optimal combination of machining process parameters. The number of experiments is reduced to minimize the cost and time using orthogonal array (OA). In the Taguchi method, the difference of functional value and objective value is emphasized and identified as the loss function. The loss function is derived as Equation. (2)

$$
L(y)=\frac{L^{\prime \prime}(m)(y-m)^{2}}{2 !}=k(y-m)^{2}=k(M S D)
$$

where $L(y)$ is the loss function, $y$ is the value of the quality characteristic, $m$ is the target value of $y, k$ the proportionality constant which depends on financial criticality of $y$ and $M S D$ is the mean square deviation. Equation. (2) can be expressed by the signal-to-noise ratio $(\mathrm{S} / \mathrm{N}$ ratio or $\eta)$ and can be rewritten as given in Equation. (3) as:

$$
\eta=-10 \log _{10}(M S D)
$$

In the case of $\mathrm{F}_{\mathrm{d}}$, smaller values are preferred. The equation for calculating $\mathrm{S} / \mathrm{N}$ ratio $\eta$ for smaller-thebetter characteristic (in decibels) is given in Equation. (4) as:

$$
\eta=-10 \log _{10}\left[\frac{1}{n} \sum_{i=1}^{n} Y_{i}^{2}\right] i=1,2, \ldots, n
$$

where $\mathrm{Y}_{\mathrm{i}}$ is the value of Fd for the $i^{\text {th }}$ test in that trial, ' $n$ ' the number of tests [14]. High signal-to-noise ratios are always 


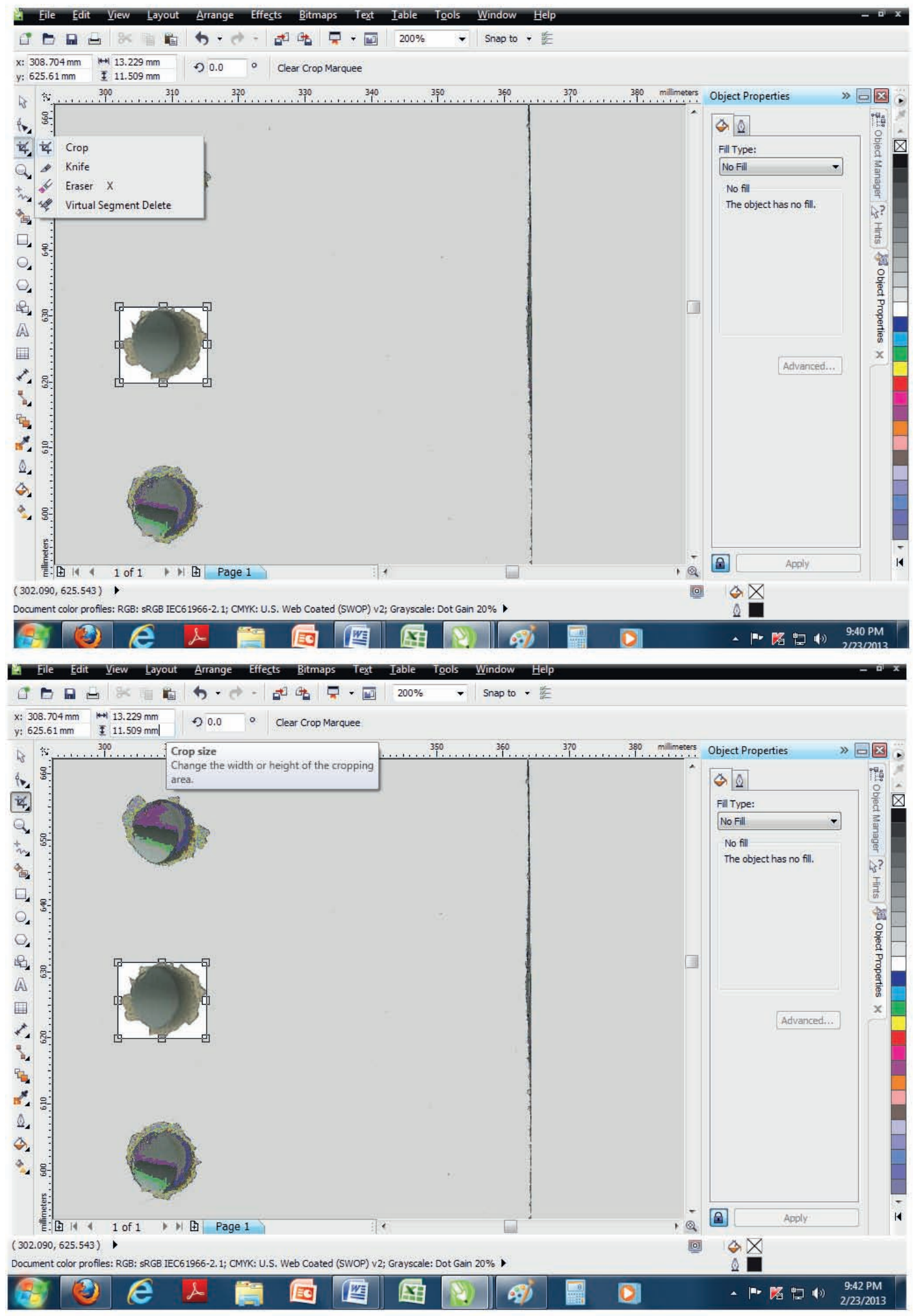

Figure 2. (a) Typical CorelDRAW X5 images used to measure the delamination of drilled hole and 

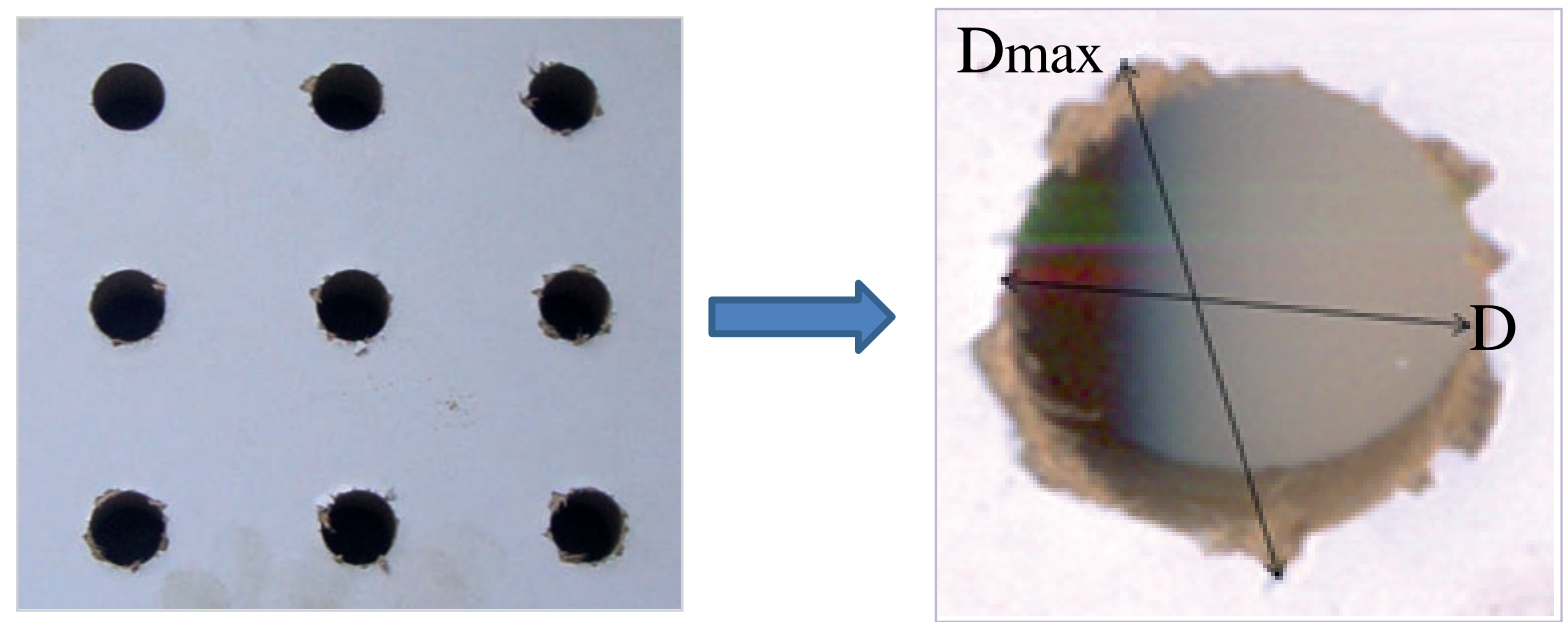

Figure 2. (b) Drilled holes and the scheme of delamination.

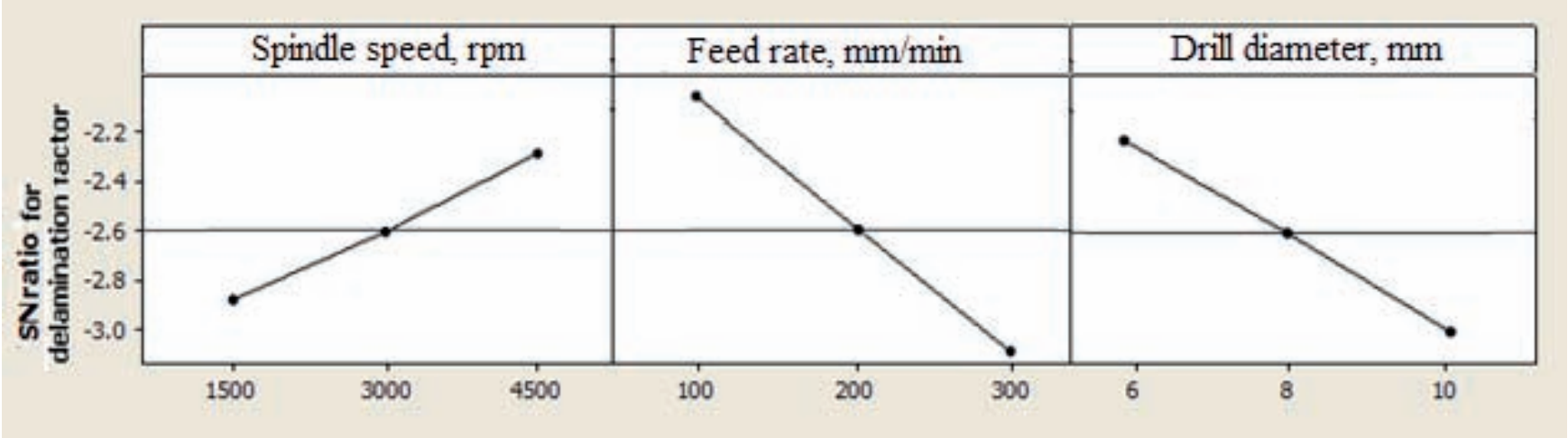

Figure 3. Main effects plots for $\mathrm{S} / \mathrm{N}$ ratios of spindle speed, feed rate and diameter on $\mathrm{F}_{\mathrm{d}}$.

preferred in a Taguchi experiment. For lower-the-better characteristic, this translates into lower process average and improved consistency from one unit to the next or both. The $\mathrm{S} / \mathrm{N}$ ratios are calculated for delamination in drilling of wood composite panels. Using the average $\mathrm{S} / \mathrm{N}$ values, the main effect plot is drawn as shown in Figure 3. From Figure 3, it is observed that the values of $\mathrm{S} / \mathrm{N}$ ratio are higher for $4500 \mathrm{rpm}$ spindle speed, $100 \mathrm{~mm} / \mathrm{min}$ feed rate and $6 \mathrm{~mm}$ drill diameter. Hence it is revealed that the appropriate cutting conditions for minimizing the delamination are high spindle speed, low feed rate and smaller drill diameter. The results of the ANOVA for $\mathrm{S} / \mathrm{N}$ ratios are presented in Table 3. The F-values indicates that the effect of feed rate is more (214.1) on delamination followed by drill diameter (131.39) and spindle speed (75.32) in drilling of MDF panels.

\subsection{Response Surface Methodology}

RSM is a method of statistical and mathematical techniques. RSM is used to analyze the problems, in which one or more responses are influenced by many factors and to find out the quantitative relationship between the response variables and the input control variables. In engineering applications, there is a relationship between the response ' $y$ ' and a set of influencing variables $\left\{x_{1}, x_{2}, \ldots, x_{n}\right\}$. The nature of the relationship between $y$ and $x$ values can be written as in the Equation. (5) as:

$$
y=f\left(x_{1}, x_{2}, \ldots, x_{n}\right)+\varepsilon
$$

where $\varepsilon$ represents the error. If the expected response be $\mathrm{E}(\mathrm{y})=f\left(x_{1}, x_{2}, \ldots, x_{n}\right)=\hat{y}$, then the surface represented by the Equation. (6) as 
Table 3. Results of the ANOVAfor $\mathrm{S} / \mathrm{N}$ ratios

\begin{tabular}{lrlllll}
\hline Source & DF & Seq SS & Adj SS & Adj MS & F & P \\
\hline Spindle speed & 2 & 1.09757 & 1.09757 & 0.54879 & 75.32 & 0.000 \\
Feed rate & 2 & 3.11973 & 3.11973 & 1.55987 & 214.10 & 0.000 \\
Diameter & 2 & 1.91458 & 1.91458 & 0.95729 & 131.39 & 0.000 \\
$\begin{array}{l}\text { Spindle } \\
\text { speed }^{*} \text { Feed rate }\end{array}$ & 4 & 0.21872 & 0.21872 & 0.05468 & 7.50 & 0.008 \\
$\begin{array}{l}\text { Spindle speed } \\
\text { Diameter }\end{array}$ & 4 & 0.04375 & 0.04375 & 0.01094 & 1.50 & 0.289 \\
Feed rate* & 4 & 0.07062 & 0.07062 & 0.01766 & 2.42 & 0.133 \\
$\begin{array}{l}\text { Diameter } \\
\text { Residual Error }\end{array}$ & 8 & 0.05829 & 0.05829 & 0.00729 & & \\
Total & 26 & 6.52326 & & & & \\
\hline
\end{tabular}

$$
\hat{y}=f\left(x_{1}, x_{2}, \ldots, x_{n}\right)
$$

is called response surface. The first step in RSM is to find a suitable approximation for the true functional relationship between $y$ and the set of independent variables employed. A second order model is normally utilized in response surface methodology $[15,16]$ is given in Equation. (7) as:

$$
\hat{y}=\beta_{0}+\sum_{i=1}^{k} \beta_{i} x_{i}+\sum_{i=1}^{k} \beta_{i i} x_{i}^{2}+\sum_{i} \sum_{j} \beta_{i j} x_{i} x_{j}+\varepsilon
$$

The $\beta$ coefficients, used in the above model can be calculated by means of using least square method.

\subsection{RSM Mathematical Model}

In this investigation a mathematical model is developed using RSM to determine the relationship between the control and response variables. The model summary is given in Table 4 . The coefficient of determination $\left(\mathrm{R}^{2}\right)$ was determined to check the adequacy of fit of the model and it was found to be 0.9529 . The RSM model is established to obtain the relation between the delamination and drilling parameters and the developed model equation is given in Equation. (8).

Delamination Factor $(F d)$

Table 4. Model summary

\begin{tabular}{lccccc}
\hline Source & S & R-Sq & R-Sq(adj) & R-Sq(pred) & PRESS \\
\hline Regression & 2.0772 & 0.9529 & 0.9279 & 0.8641 & 211.462 \\
\hline
\end{tabular}

$$
\begin{aligned}
\left(F_{d}\right)= & 1.19407-4.14815 E-05^{\star} N+0.000400^{\star} f \\
& +0.01250 \star d-9.87654 E-10^{\star} N^{2} \\
& +1.11111 E-07^{\star} f^{2}+0.00069444^{\star} d^{2} \\
& +7.77778 E-08^{\star} N^{\star} f+8.3333 E \\
& -07^{\star} N^{\star} d-4.16667 E-06^{\star} f^{\star} d
\end{aligned}
$$

Figure 4 shows the Normal probability plot of residual. From normal probability plot it is noticed that the data are spread approximately in a straight line, which shows good correlation between the experimental and predicted values.

The correlation graph for actual $F_{d}$ and predicted $F_{d}$ is shown in Figure 5. From the figure it is observed that the predicted values for $F_{d}$ are very close to the actual measured values of delamination and hence the developed model is effective to predict the delamination in drilling of MDF wood composite panels. The ANOVA is carried out to check the adequacy of the model. The results of the ANOVA for the $\mathrm{F}_{\mathrm{d}}$ are presented in Table 5. The model F-value 38.18 indicates that the model is significant with the probability of $<0.0001$.

\subsection{Effect of Factors and Their Interaction}

The drilling of wood composite panels develops delamination damage which reduces the aesthetic appearance

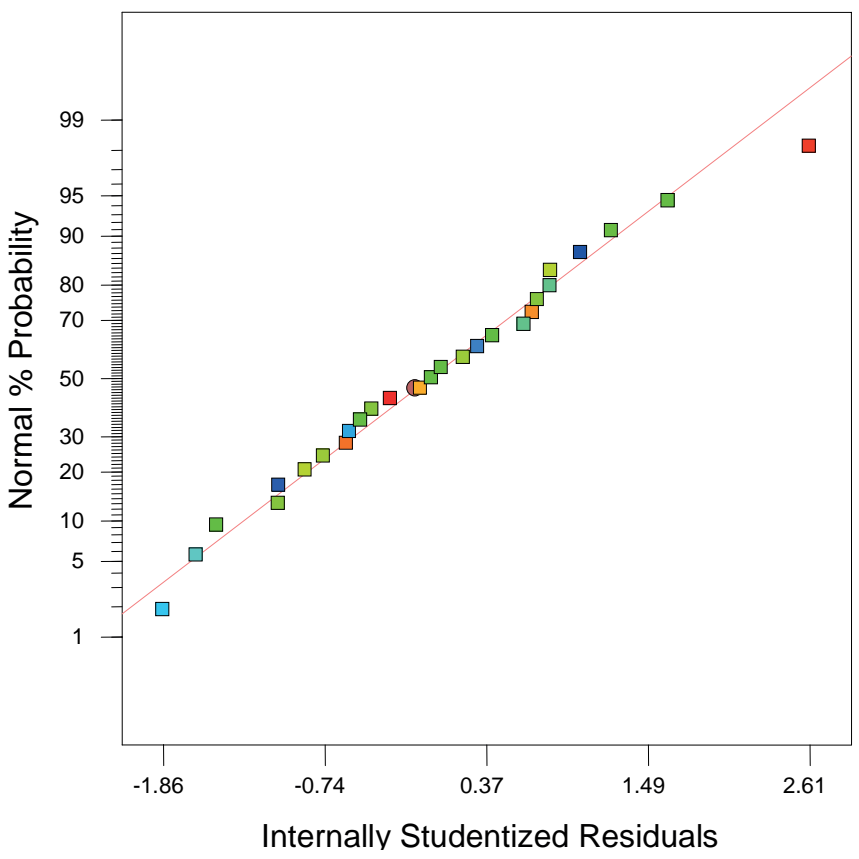

Figure 4. Normal probability plot of residual. 
and the final performance of the product. This delamination is due to the effect of control parameters and the interaction between the parameters. Hence the control

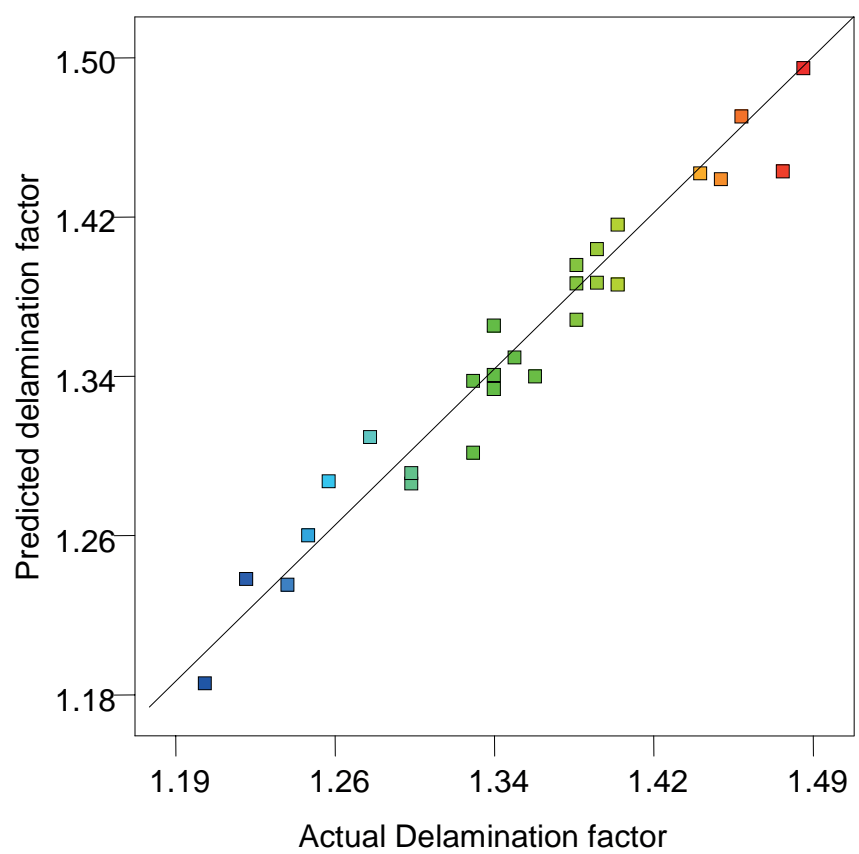

Figure 5. Correlation graph for Fd.

Table 5. Results of the ANOVA for $\mathrm{F}_{\mathrm{d}}$

\begin{tabular}{lrrrrrr}
\hline Source & DF & Seq SS & Adj SS & Adj MS & F & P \\
\hline Regression & 9 & 0.148250 & 0.148250 & 0.016472 & 38.18 & $<0.0001$ \\
Linear & 3 & 0.146450 & 0.146450 & 0.048817 & 113.14 & $<0.0001$ \\
Square & 3 & 0.000083 & 0.000083 & 0.000028 & 0.06 & 0.978 \\
Interaction & 3 & 0.001717 & 0.001717 & 0.000572 & 1.33 & 0.299 \\
Residual & 17 & 0.007335 & 0.007335 & 0.000431 & & \\
Error & & & & & & \\
Total & 26 & 0.155585 & & & & \\
\hline
\end{tabular}

of parameters is very much essential in drilling of wood composite panels.

Figure 6 shows the influence of various drilling process parameters on delamination in drilling of wood panels. From Fig. 6, it is observed that all the three factors have some effect on the delamination and it is more when the spindle speed is low and the feed rate and drill diameter is high. The increase in the magnitude of $F_{d}$ is high for feed rate and drill diameter when compared to the decrease in the magnitude of delamination for spindle speed. Hence it is evident that the dominant factors for the increasing tendency of delamination in drilling of wood composite panels are feed rate and diameter followed by spindle speed.

Figure 7 (a, b and c) show the surface plots for the $F_{d}$ in drilling of wood composite panels with HSS drills of three different drill diameters for the middle level hold values. From Figure 7(a) it is observed that the $F_{d}$ is decreased when the spindle speed is increased and the feed rate is decreased. From Figure $7(b)$ it is observed that the $F_{d}$ is decreased when the feed rate and also the drill diameter are decreased.

From Figure 7(c) it is observed that the $\mathrm{F}_{\mathrm{d}}$ is decreased when the spindle speed is higher and the drill diameter is low.The mechanism behind this is at low cutting speeds and high feed rates the fracture of the chips is more and the thrust force developed is high which leads to the increase in the delamination tendency. On the other hand at higher cutting speeds, the thermal softening of work material takes place due to the high temperature generation which in turn reduces the built-up edge and the cutting force required to shear the material and hence the minimum delamination [5]. Hence it is revealed that the high spindle speed, low feed rate and small drill diameter can reduce the effect of delamination tendency in drilling of MDF panels.

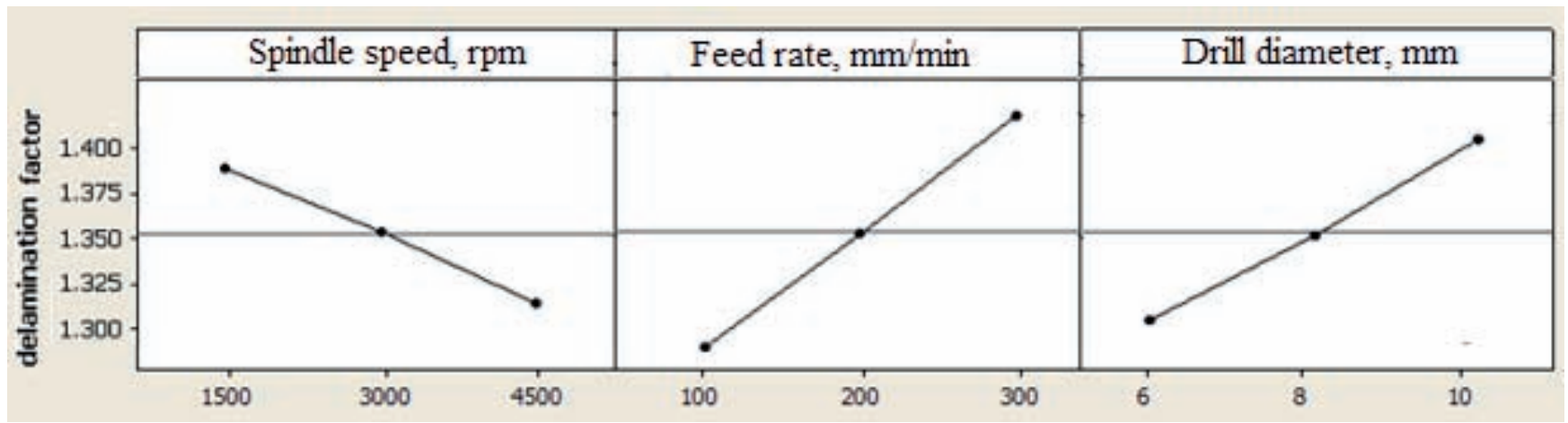

Figure 6. Main effects plots for means of spindle speed, feed rate and diameter on $\mathrm{F}_{\mathrm{d}}$. 


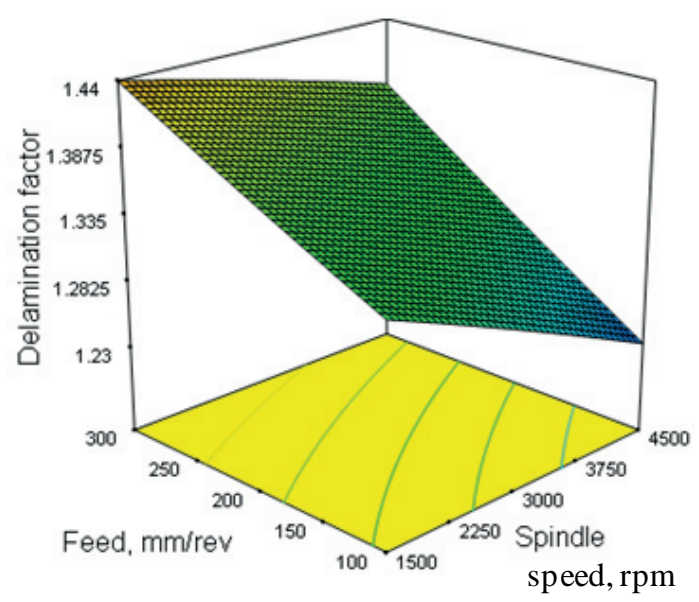

(a)

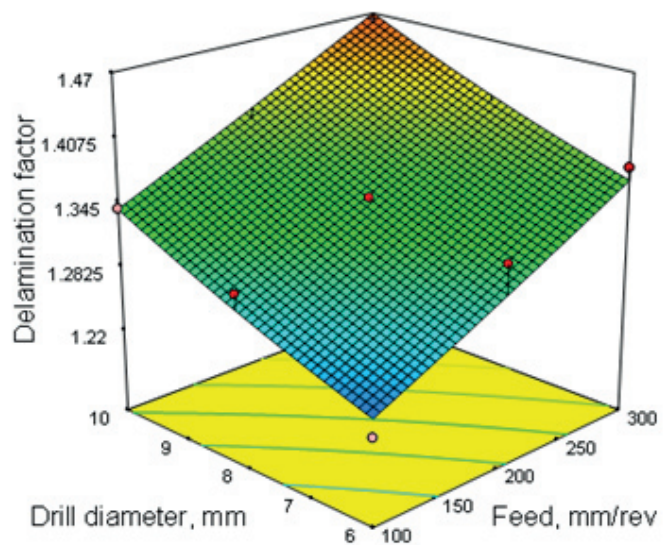

(b)

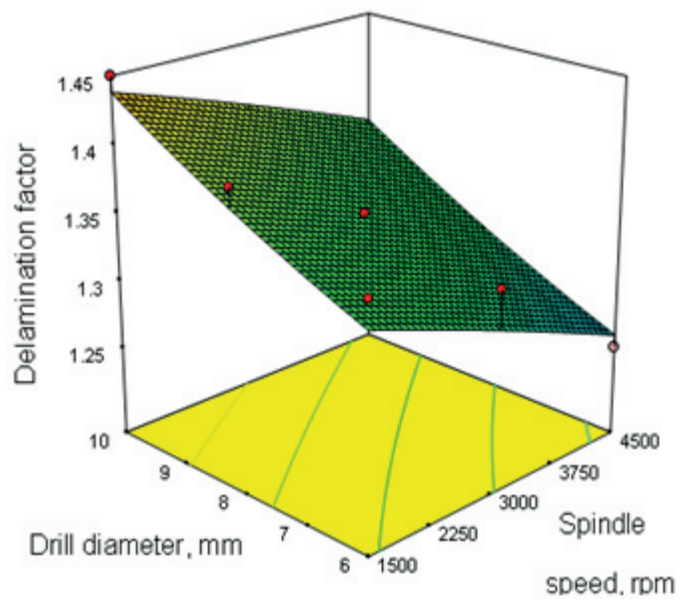

(c)

Figure 7. Surface plots (a) spindle speed vs feed rate (b) diameter vs spindle speed and (c) diameter vs feed rate.

Figure 8 ( $\mathrm{a}, \mathrm{b}$ and $\mathrm{c}$ ) show the contour plots for the $\mathrm{F}_{\mathrm{d}}$. From Figure 8(a) it is observed that the $\mathrm{F}_{\mathrm{d}}$ is less when the feed rate is low and the spindle speed is high value. From Figure $8(\mathrm{~b})$ it is observed that the $\mathrm{F}_{\mathrm{d}}$ is less when the spindle speed is high and the diameter is low value. From Figure $8(c)$ it is observed that the $\mathrm{F}_{\mathrm{d}}$ is less when the diameter and the feed rate are low. Hence it is concluded that the high spindle speed, low feed rate and small drill diameter can reduce the effect of delamination tendency. Figure 9 shows the scanning electron micrograph of before and after drilling of MDF panel.

\section{Conclusion}

In this study, the drilling experiments were performed on wood composite panels using Taguchi design of experiments and a mathematical model was developed using RSM. Based on the experimental results, Taguchi technique and the mathematical model developed using RSM technique, the following conclusions can be drawn in drilling of wood composite panels with HSS twist drills:

- From main effects plots for $\mathrm{S} / \mathrm{N}$ ratios and means it is evident that the delamination developed is decreased with increase of spindle speed and it is less at $4500 \mathrm{rpm}$. The delamination developed is decreased with decrease of feed rate and drill diameter. It is less at feed rate is $100 \mathrm{~mm} / \mathrm{min}$ and drill diameter is $6 \mathrm{~mm}$.

- The feed rate and drill diameter are the most dominant factors followed by the spindle speed on delamination.

- Apart from the main variables the interactions between the process parameters also have some effect on the delamination in drilling of wood composite panels. 


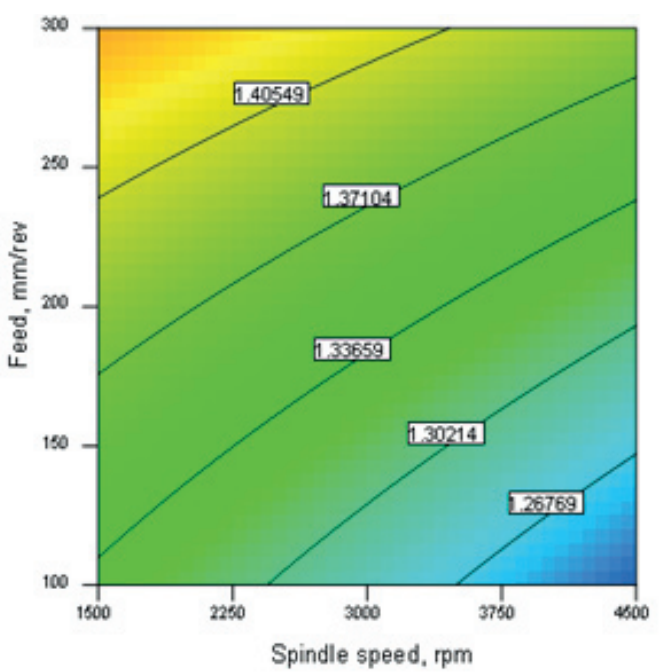

(a)

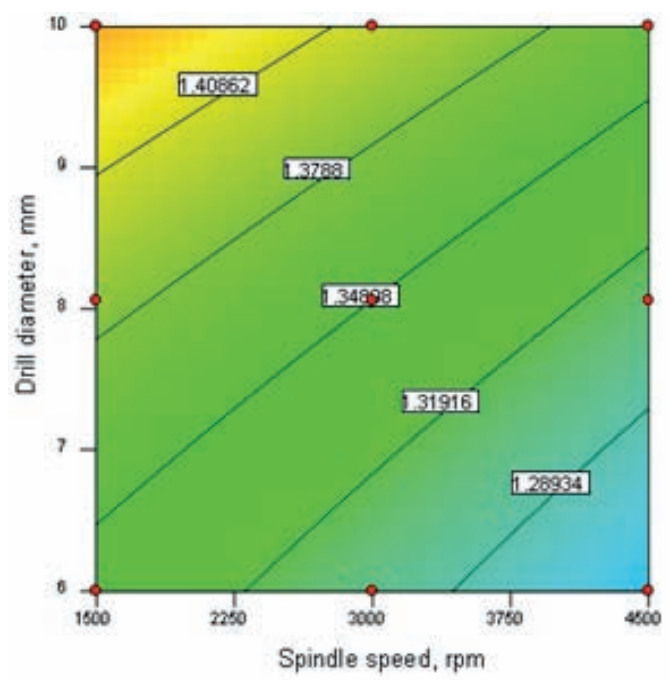

(b)

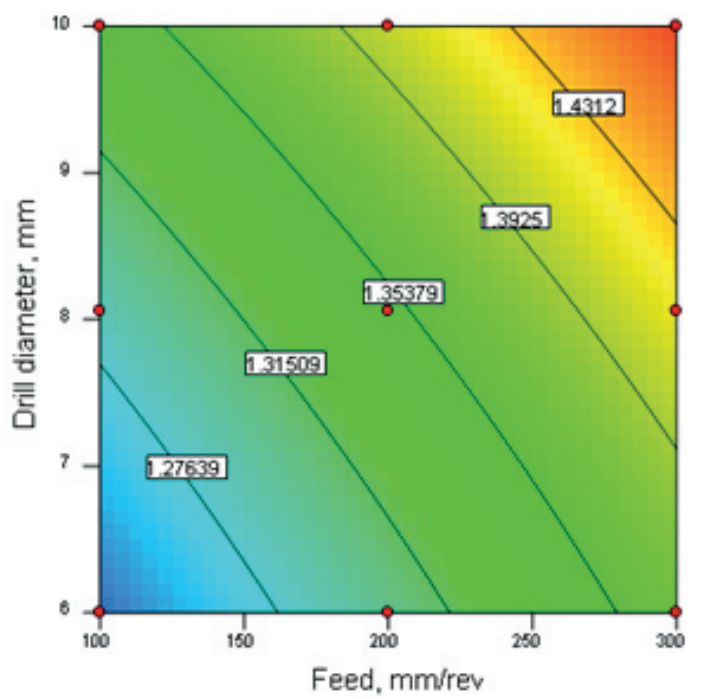

(c)

Figure 8. Contour plots (a) spindle speed vs feed rate (b) diameter vs spindle speed and (c) diameter vs feed rate.

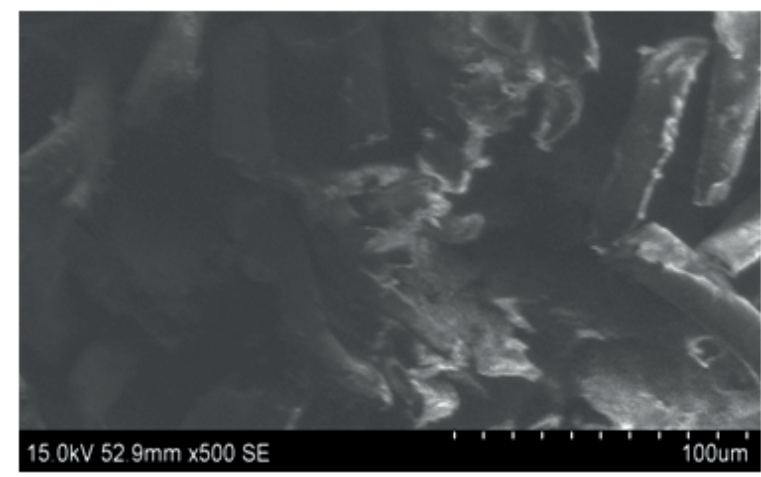

(a)

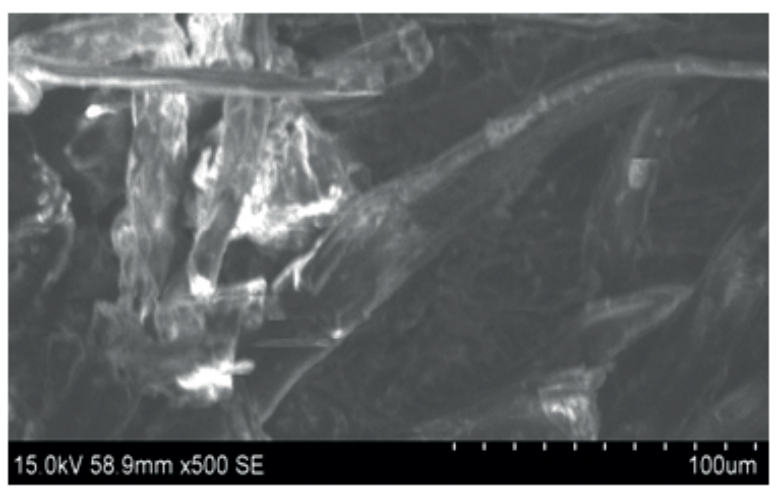

(b)

Figure 9. SEM images of MDF panels (a) before and (b) after drilling. 
- The optimal conditions for minimizing the delamination are high spindle speed $(4500 \mathrm{rpm})$, low feed rate $(100 \mathrm{~mm} / \mathrm{min})$ and small drill diameter $(6 \mathrm{~mm})$ combinations within the range of levels and factors considered for this experimental work.

\section{References}

1. Aguilera A, Meausoone P J et al. (2000). Wood material influence in routing operations: the MDF case, Holz als Rohund Werkstoff, vol 58(4), 278-283.

2. Davim J P, Clemente V C et al. (2007). Evaluation of delamination in drilling medium density fibre board, Proceedings of the Institution of Mechanical Engineers, Part B: Journal of Engineering Manufacture, vol 221(4), 655-658.

3. Davim J P, Clemente V C et al. (2008). Drilling investigation of MDF (Medium Density Fibre Board), Journal of Materials Processing Technology, vol 203(1-3), 537-541.

4. Davim J P, Gaitonde V N et al. (2008c). An investigative study of delamination in drilling of medium density fibre board (MDF) using response surface models, The International Journal of Advanced Manufacturing Technology, vol 37(1-2), 49-57.

5. Gaitonde V N, Karnik S R et al. (2008). Prediction and minimization of delamination in drilling of medium-density fiberboard (MDF) using response surface methodology and Taguchi design, Materials and Manufacturing Processes, vol 23(4), 377-384.

6. Gaitonde V N, Karnik S R et al.(2008). Taguchi multiple-performance characteristics optimization in drilling of medium density fiberboard (MDF) to minimize delamination using utility concept, Journal of Materials Processing Technology, vol 196(1-3), 73-78.

7. Tsao C C (2008). Thrust force and delamination of core-saw drill during drilling of carbon fiber reinforced plastics (CFRP), The International Journal of Advanced Manufacturing Technology, vol 37(1-2), 23-28.
8. Singh R V S, Latha B et al.(2009). Modeling and Analysis of Thrust Force and Torque in Drilling GFRP Composites by Multi-Facet Drill Using Fuzzy Logic, International Journal of Recent Trends in Engineering, vol 1(5), 66-70.

9. Palanikumar K, Prakash S et al. (2009). Experimental investigation and analysis on delamination in drilling of wood composite medium density fiber boards, Materials and Manufacturing Processes, vol 24(12), 1341-1348.

10. Prakash S, and Palanikumar K (2011). Modeling for Prediction of surface roughness in drilling MDF panels using response surface methodology, Journal of Composite Materials, vol 45(16), 1639 -1646.

11. Valarmathi T N, and Palanikumar K (2011). Evaluation of thrust force in drilling of medium density fiberboard (MDF) panels,National Journal on Advances in Building Sciences and Mechanics, vol 2(1), 53-60.

12. Valarmathi T N, Palanikumar K et al. (2012). Modeling of thrust force in drilling of plain medium density fiberboard (MDF) composite panels using RSM, Proceedia Engineering, vol 38, 1828-1835.

13. Valarmathi T N, Palanikumar K et al. (2013). Thrust force studies in drilling of medium density fiberboard panels, Advanced Materials Research, vols 622-623, 1285-1289.

14. Palanikumar K (2008). Application of Taguchi and response surface methodologies for surface roughness in machining glass fiber reinforced plastics by PCD tooling, International Journal of Advanced Manufacturing Technology, vol 36(1-2), 19-27.

15. Ramesh S, Karunamoorthy L et al. (2008). Surface roughness analysis in machining of titanium alloy, Materials and Manufacturing Processes, vol 23(2), 174-181.

16. Hussain S A, Pandurangadu V et al. (2011). Cutting power prediction model for turning of GFRP composites using response surface methodology, International Journal of Engineering, Science and Technology, vol 3(6), 161-171. 